\title{
ALCOHOL, DRUGS AND PSYCHOTROPIC MEDICATION AT WORK: GUIDELINES FOR MEDICAL FITNESS
}

\author{
Milan Tuček ${ }^{1}$, Alenka Škerjanc ${ }^{2}$ \\ ${ }^{1}$ Institute of Hygiene and Epidemiology, First Faculty of Medicine, Charles University and General University Hospital, Prague, Czech Republic \\ ${ }^{2}$ University Medical Centre Ljubljana, Clinical Institute for Occupational, Traffic and Sports Medicine, Ljubljana, Slovenia
}

\begin{abstract}
SUMMARY
Alcohol and illicit drug use in the workplace is a relatively widespread but still insufficiently recognised phenomenon. The reliability of judgement and performance of workers especially undertaking safety-critical tasks must not be influenced by physical, mental and/or behavioural disturbances. It is the responsibility of a company to define and implement proper policy for managing safety risks related to the influence of alcohol, drugs and/ or psychotropic medication. Occupational physicians are already involved in the process of prevention in these matters. Authors describe basic recommendations of two biggest international associations of occupational physicians in this field because workers may not perform safety-critical tasks under the influence of psychotropic substances such as alcohol, illicit drugs and psychotropic medication.
\end{abstract}

Key words: alcohol, illicit drugs, psychotropic substances, medical examination, testing, medical fitness

Address for correspondence: M. Tuček, Institute of Hygiene and Epidemiology, First Faculty of Medicine, Charles University, Studničkova 7 , 12000 Prague 2, Czech Republic. E-mail: milan.tucek@lf1.cuni.cz

https://doi.org/10.21101/cejph.a5857

\section{INTRODUCTION}

Alcohol, illicit drugs and psychotropic substances either stimulate or inhibit the central nervous system or cause hallucinogenic effects. The Section of Occupational Medicine of the European Union of Medical Specialists (French acronym UEMS) and the International Union of Railway Medical Services (French acronym UIMC) recommend that employers describe and apply the advisory role of medical specialists in occupational medicine. It also considers that alcohol and drug prevention needs both an individual and collective approach: it is a health promotion policy as well as a safety policy and the roles and responsibilities of the different stakeholders must be clearly defined (1-3).

\footnotetext{
Alcohol

Because of its influence on mental and/or motor function it is strongly recommended that no alcohol in blood is allowed while on duty. For that reason alcohol consumption during or before duty cannot be accepted. It is medically known that above an alcoholemia of $0.2 \mathrm{~g} / \mathrm{L}$ negative effects can be observed.

Chronic alcoholism influences behaviour for extended period of time and the reaction capacity of the person concerned. For this reason, it must be considered as an absolute contraindication to performing safety work. Negative effects at low levels of alcoholemia cannot be excluded because of individual susceptibility. It is generally recommended to respect an alcoholemia of 0.0 $\mathrm{g} / \mathrm{L}$. Self-testing and company organized testing with a breathalcohol analyzer is recommended. Alcohol consumption can be
}

estimated by a medical history, examination, validated scales use (Fast Alcohol Consumption Evaluation, Alcohol Use Disorders Identification Test) $(4,5)$, and biological tests (mean corpuscular erythrocyte volume MCV, gamma-glutamyl transferase GGT, transaminases AST (aspartate aminotransferase) and ALT (alanine aminotransferase), carbohydrate-deficient transferrin CDT, ethyl glucuronide EtG and/or phosphatidylethanol PEth in blood). After treatment and rehabilitation of the chronic alcoholism it is up to the occupational physician to decide when the affected person may resume safety work.

Strong disqualifying criteria: alcohol-use disorders - regular abusive consumption and dependence.

Relative disqualifying criteria: unhealthy use - problem drinking (binge drinking) and risky use. The National Institute on Alcohol Abuse and Alcoholism (NIAAA) defines binge drinking as consuming roughly 5 or more drinks for men and 4 or more for women in short period of time (about 2 hours), it means drinking large amounts of alcohol to the point of legal intoxication. Risky drinking NIAAA defines as consuming more than 3 drinks on any day or 7 drinks in a week for women, more than 4 drinks on any day or 14 drinks in a week for men.

The fitness of safety-critical tasks can be discussed after a validated abstinence of at least 6 months. EtG is a direct marker for alcohol intake before recovering the ability for safety-critical tasks; it is recommended to control the abstinence with EtG measurements in blood, urine or hair (UIMC recommendation).

In case of chronic alcoholism, specific medical follow-up must be organized including psychological assessment (regular medical assessment and laboratory testing for at least a year). 
Abstinence assessment is possible with EtG (blood, urine or hair) or PEth (blood).

\section{Drugs}

Any intake of illicit drugs is hazardous to personal health and behaviour with respect to personal and public safety. There is an absolute contraindication to performing safety work (6). 1t is the responsibility of the occupational physician to make an individual evaluation of each case after rehabilitation before authorizing the affected person to return to safety work.

The test in the urine (immunoassay) is the standard screening test. The saliva testing (immunoassay) or the blood test could be used to check an acute influence.

In case of a positive test, it is also possible to confirm the results by liquid chromatography (LC) or gas chromatographymass spectrometry (GC/MS). The cut-off of the blood levels are the following : $1.5 \mu \mathrm{g} / \mathrm{L}$ for $\mathrm{THC}$ and $15.0 \mu \mathrm{g} / \mathrm{L}$ for morphine, cocaine and amphetamine.

THC-COOH (11-nor-9-carboxy- $\Delta$ 9-tetrahydrocannabinol) in blood is recommended to make the difference between a sporadic and a regular cannabis consume. A very high concentration of THC-COOH $>40 \mu \mathrm{g} / \mathrm{mL}$ in whole blood or $64 \mu \mathrm{g} / \mathrm{L}$ in plasma indicates regular and important cannabis consumption.

Strong disqualifying criteria:

- Any use of drugs

- Any use of psychotropic drugs not in accordance with a doctor's prescription

Relative disqualifying criteria:

- Occasional cannabis consumption (fitness to undertake safetycritical tasks will be recovered if the worker abstains from any use of drugs and this is confirmed by regular random testing)

- Use of psychotropic drugs in accordance with a doctor's prescription

Drug use can be estimated by a medical history, examination, validated scales use (Cannabis Abuse Screening Test) (8), and biological tests (urine, blood, hair). Drug addiction requires a medical assessment; psychological evaluation for safety-critical tasks is strongly recommended. The medical follow-up must be organized - regular medical assessment and laboratory testing for at least 12 months. Reevaluation of the fitness to undertake safety critical tasks can be determined after a validated abstinence of at

Table 1. Recommendation for systematically screening of substances in urine

\begin{tabular}{|l|c|c|}
\hline Test & Calibrator & Cut-off* \\
\hline Amphetamine (AMP) & d-Amphetamine & $500 \mathrm{ng} / \mathrm{mL}$ \\
\hline Cocaine (COC) & Benzoylecgonine & $150 \mathrm{ng} / \mathrm{mL}$ \\
\hline Cannabis (THC) & 11-nor- $\Delta 9-\mathrm{THC}-9 \mathrm{COOH}$ & $50 \mathrm{ng} / \mathrm{mL}$ \\
\hline Methamphetamine (MET) & d-Methamphetamine & $500 \mathrm{ng} / \mathrm{mL}$ \\
\hline Morphine (MOP) & Morphine & $300 \mathrm{ng} / \mathrm{mL}$ \\
\hline Benzodiazepine* & Oxazepam & $100 \mathrm{ng} / \mathrm{mL}$ \\
\hline Methadone* $^{*}$ & Methadone & $250 \mathrm{ng} / \mathrm{mL}$ \\
\hline Buprenorphine* $^{*}$ & Buprenorphine & $5 \mathrm{ng} / \mathrm{mL}$ \\
\hline
\end{tabular}

${ }^{*}$ Possible tests in specific cases

${ }^{* *}$ European Workplace Drug Testing Society (EWDTS) (7) least 12 months, based on individual evaluation. Hair testing may also be used to assess abstinence from drug use.

\section{Psychotropic Substances}

Any prescribed medication with the ability to influence vigilance, cognitive function and/or motor function identified as being contraindicated for instance to motor driving by the national pharmaceutical authority must be carefully evaluated.

There is a double responsibility of the worker: he/she is responsible to inform the prescribing physician about his/her safety work. If the physician prescribes any psychotropic medication, the worker is responsible to inform the occupational physician in order to evaluate his/her fitness for work. The evaluation of the fitness must also consider the mental/psychiatric diseases (1).

\section{Role of Occupational Physicians}

The occupational physician plays an important part in the alcohol and drug policy of the company. The physician has to be involved in information and education of the staff and of the employees, and in the detection and follow up of the affected persons. The occupational physician evaluates the temporary or permanent unfitness for work on the basis of the collected data, symptoms and signs and test results. Although there are recommendations of international institutions made by consensus of experts, specific national legislation is binding for physicians. An example of this is the recent requirement (July 2019) of the Czech legislation to carry out so called orientation examination for the presence of psychoactive substances at every occupational medical examination of a railway employee, which is not explained or specified in any way.

\section{Medical Recommendation}

Chronic alcoholism and drug addiction must be considered as illnesses. The work of the medical services is aiming at protecting the health of employees, preventing accidents to individuals, eliminating railway traffic accidents, and facilitating occupational rehabilitation when an employee has been removed from certain critical positions.

As with any other action performed by the medical service, the detection and treatment of alcoholism and drug addiction must be conducted with the utmost respect for the principles of medical confidentiality.

Positive screening tests are not sufficient to take a final decision about the ability of the worker to perform safety work unless the positive result has been confirmed by a second more specific technique.

\section{CONCLUSIONS}

The rate of tolerance or zero tolerance for alcohol and illicit drugs must be defined and declared by the employer in order to assure the safety of the workers (3). Testing for alcohol and/or illicit drug use must follow international legislation and guidelines like the Guidance on managing safety risks related to the Influence of Alcohol, Drugs and/or Psychoactive Medication (2). The 
employer has to inform the employee that he is willing to ask a test if he suspects the employee not respecting the alcohol and drug policy and to define the consequences of no respect. Both the employers and employees are key players in detecting alcohol and illicit drug use of the workers. It should be their obligation to keep their eyes open and direct such a worker to the appropriate instance where he/she should get help to solve his problems. Undoubtedly, current tendencies display more common use of alcohol and illicit drugs at work-related meetings and activities taking place outside work itself. There are several means to interact and help workers: the legislative level, human resources department responsible person of the employer, advisors (medical specialists in occupational medicine) who are designated to help the workers to recognize their problems and to define the aims of their solve. The employer's responsibility is to define the level of tolerance of alcohol and illicit drugs on the workplace and it is the medical specialists in occupational medicine responsibility to advise both the employer and the employee on how to address these issues at the workplace. Evaluation - from defining the objectives, means and results - must be the joint activity of employers, employees and occupational medicine services.

\section{Acknowledgements}

The study was supported by the programme PROGRES Q25/LF1, Charles University, Prague.

\section{Conflict of Interests}

None declared

\section{REFERENCES}

1. UIMC Railway medical guidelines. Guidelines for medical fitness of railway personnel in safety critical functions. Paris: International Union of Railways; 2019

2. International Union of Railways. Guidance on managing safety risks related to the Influence of alcohol, drugs and/or psychoactive medication. Paris: Railway Technical Publications; 2012.

3. Škerjanc A. UEMS statement on preventing alcohol and illicit drug use in the workplace. Brussels: Union Européenne des Médecins Spécialistes; 2014.

4. Hodgson R, Alwyn T, John B, Thom B, Smith A. The FAST alcohol screening test. Alcohol. 2002(37):61-6.

5. Babor TF, Higgins-Biddle JC, Saunders J, Monteiro MG. AUDIT: the alcohol use disorders identification test: guidelines for use in primary care. 2nd ed. Geneva: WHO; 2001.

6. Tuček M. Transport safety, neurobehavioral disorders and medical fitness standards. Neural Network World. 2010;6(10):723-36.

7. European Workplace Drug Testing Society. European Guidelines for Workplace Drug Testing in Urine, 2015-11-01 Version 2.0 [Internet]. EWDTS; 2015 [cited 2019 Jun 6]. Available from: http://www.ewdts. org/data/uploads/documents/ewdts-urine-guideline-2015-11-01-v2.0.pdf.

8. Legleye S, Karila L, Beck F, Reynaud M. Validation of the CAST, a general population Cannabis Abuse Screening Test. J Subst Use. 2007;12(4):233-42. 